\title{
An Introduction to Journal Club in The Cerebellum
}

\author{
Roy V. Sillitoe
}

Published online: 21 October 2012

(C) Springer Science+Business Media New York 2012

The cerebellum shapes motor function by controlling coordination, balance, and learning. Recently, imaging and behavior studies have demonstrated that the cerebellum also participates in non-motor functions by modulating language, emotion, and cognition. Driving the field is now an exciting interplay between these basic science studies and a rapidly growing translational research literature showing that defects in cerebellar function contribute to a variety of brain conditions such as ataxia, dystonia, tremor, multiple sclerosis, and autism spectrum disorders. Realizing the breadth and exponential pace at which cerebellar research is advancing, The Cerebellum editorial team decided to harness this momentum in discovery and develop a new forum to promote ideas, critical thinking, and collaboration in cerebellar research. We developed a new section in The Cerebellum devoted to journal club articles to review and discuss recent groundbreaking work in the field. We are delighted to announce that our inaugural article upholds our vision [1]. Postdoctoral fellows Dr. Stacey L. Reeber (Baylor College of Medicine, TX) and Dr. Kevin O’Donovan (Weill Cornell Medical Center, NY) have published an excellent journal club paper discussing the work of developmental biologist and pioneer molecular geneticist Dr. Alexandra L. Joyner (Sloan-Kettering Institute, NY) [2]. This journal club paper focused the spotlight on the origins of cerebellar lineages and highlighted how embryonic gene function determines adult circuit diversity.

\footnotetext{
R. V. Sillitoe $(\varangle)$

Department of Pathology and Immunology,

Baylor College of Medicine, Jan and Dan Duncan Neurological

Research Institute of Texas Children's Hospital,

1250 Moursund street, Suite 1325,

Houston, TX 77030, USA

e-mail: sillitoe@bcm.edu

R. V. Sillitoe

Department of Neuroscience,

Baylor College of Medicine, Jan and Dan Duncan Neurological

Research Institute of Texas Children's Hospital,

1250 Moursund street, Suite 1325 ,

Houston, TX 77030, USA
}

Dr. Roy V. Sillitoe, editor for the Neural Development section of the journal, will also serve as the editor for journal club submissions. We invite manuscripts from postdoctoral fellows, graduate students, residents, and fellows in all areas of cerebellar research, including but not limited to development, genetics, genomics, electrophysiology, imaging, computation, anatomy, neuropathology, neurology, and neurosurgery. We encourage authors to discuss, compare, and contrast between model organisms such as rodents, Drosophila, Caenorhabditis elegans, chick, and primate. Given the interconnectivity of the cerebellum with dozens of regions in the brain and spinal cord, we are also happy to consider "systems" level papers that deal with brain network connections with cerebellar involvement. Authors should highlight the technical and conceptual advances of the publication(s) they have chosen and discuss new directions of research that were (or will be) stimulated by the results. Although we encourage authors to be honest and critical, all opinions and statements (both in the manuscript and in responses to reviewers) must be diplomatic and free of personal attacks. Manuscripts should be written in English and follow the submission guidelines of The Cerebellum (http://www.springer.com/biomed/neuroscience/journal/ 12311). Submitted manuscripts will be peer reviewed for quality and accuracy. Accepted papers will be archived in PubMed.

In closing, we are thrilled to devote an entire section of our journal to the cultivation of dialogue initiated by postdoctoral fellows, graduate students, residents, and fellows. Please contact Dr. Sillitoe with questions and inquiries about your idea for a journal club article.

\section{References}

1. Reeber SL, O'Donovan KJ. Tracking cell lineage and fate into cerebellar circuits. Cerebellum 2012. doi:10.1007/s12311-0120409-z

2. Sudarov A, Turnbull RK, Kim EJ, Lebel-Potter M, Guillemot F, Joyner AL. Ascl1 genetics reveals insights into cerebellum local circuit assembly. J Neurosci. 2011;31(30):11055-69. 